\title{
THE RELATION BETWEEN OPEN INNOVATION AND ECONOMIC PERFORMANCE OF SMES
}

\author{
*Mesut SAVRUL \\ **Ahmet INCEKARA \\ *Canakkale Onsekiz Mart University, Turkey \\ ** Istanbul University, Turkey
}

\begin{abstract}
The interest drawn by small and medium sized enterprises (SMEs) is growing all over the world since they accredits more than $95 \%$ of all firms outside the agriculture sector and they form a considerable source of employment generate significant domestic and export earnings. Although SMEs contribute significantly to the country host them, they get the greatest damage from this new business environment created by globalization. While many SMEs have indeed surrendered to deterioration of competitiveness, others started to implement open innovation as a necessary organizational adaptation to changes in the environment. In a world of mobile workers, abundant venture capital, widely distributed knowledge and reduced product life cycles, most enterprises can no long erafford to innovate on their own.
\end{abstract}

Because the funds they can allocate to $R \& D$ investment, SMEs adopt open innovation practices in which they establish external partnerships to concentrate on various technologies. These partners may be the SMEs just like themselves or the larger firms, university research centres or even non-profit organizations. However, with the fear of giving away their technology to competitors, if all of these options are available the choice of the SMEs will generally be university research centres or non-profit organizations.

In this framework this study investigates the effects of open innovation on economic performance of SMEs. The study covers turnover and GERD data from 21 EU Countries covering 2007-2014 period. The results of the study indicate that the mentioned $R \& D$ variables are responsible for $45 \%$ of the changes in turnover value of SMEs.

Keywords: Open Innovation, Globalization, SMEs

\section{INTRODUCTION}

SMEs play do minant roles in terms of employ ment generation and economic development in this regards the effects of g lobalization on them and their prosperity in new business environment created by globalization is of a particular important to both developing and developed economies. Although SMEs contribute significantly to the country host them, they get the greatest damage from the new business environment created by globalization. It is expected that the globalization and the global competition will go on growing. While many SMEs have indeed surrendered to deterioration of competitiveness, others will have to find ways to improve their positions in global markets.

In this context, many firms started to implement innovation as a necessary organizational adaptation to changes in the environment. In a world of mobile workers, abundant venture capital, widely distributed knowledge and reduced product life cycles, most enterprises can no longer afford to innovate on their own. Because the funds they can allocate to R\&D investment is limited, many SMEs adopt open innovation practices which is a paradig $m$ that assumes that firms can and should use external ideas as well as internal ideas, and internal and external paths to market, as the firms look to advance their technology. They want to establish external partnerships to concentrate on various technologies. These partners may be the SMEs just like themselves or the larger firms, university research centres or even non-profit organizations. However, with the fear of giving a way their technology to competitors, if all of these options are available the choice of the SMEs will generally be university research centres or non-profit organizations. 
Journal of Global Strategic Management | V. 9 | N. 1 | 2015-June | isma.info | 125-133 | DOI:10.20460/JGSM.2015915634

In this framework this study investigates the effects of open innovation on economic performance of SMEs. The study covers turnover and GERD (Gross domestic expenditure on R\&D) data from 21 EU Countries covering 2007-2014 period. The data is collected from OECD and Eurostat databases and data 7 of the EU countries with missing values are excluded from the analys is. The analysis is formed of 4 variables; total turnover value of SMEs is indicated by TOV, GERD by higher education by GEHI, GERD by government by GEGO and GERD by non-profit organization by GENP. The results of the study indicate that the mentioned $R \& D$ variables are responsible for $45 \%$ of the changes in turnovervalue of SMEs.

\section{SMEs and Innovation}

The interest drawn by small and medium sized enterprises (SMEs) is growing all over the world since they accredits more than $95 \%$ of all firms outside the agriculture sector and they form a considerable source of employment generate significant domestic and export earnings. SMEs create most of the business and employ the majority of workers in both manufacturing and services sectors in both developed and developing world. Although they usually operate in domestic markets and their contribution to GDP is often short due to on the value of the goods or services they produce. The recent studies signify that the benefit of these enterprises to GDP can be decisive in the countries with large SME sectors (WTO, 2013: 1; Mohammad, 2010: 66).

SMEs also have a great significance in Europe where they account for over $99 \%$ of all businesses and in recent years they are regarded as the engines of economic growth, and the principle sources of new employment. Their ability to exploit new technologies and to respond quickly to changing market needs give them a central role in the success of the European economy. Support for the creation of new ventures and spin-offs from research institutions and large companies, as well as the removal of barriers to their rapid growth and support for the transfer of know-how, also deserve to be accorded the highest priority (European Comission, 2014).

Considered as one of the most important circumstances of the 20th century, globalization is changing the economic infrastructure of the world significantly. In this new infrastructure economic activities are shifting away from a local or national sphere toward a much more international or global. Although SMEs contribute significantly to the country host them, they get the greatest damage from this new business environment created by globalization. It is expected that the globalization and the global competition will go on growing. While many SMEs have indeed surrendered to deterioration of competitiveness, others have found ways to actually enhance their positions in global markets (OECD, 2000: 4).

The thing that distinguishes them is not only their own willingness or efforts. Their adaptation to the new business environment depends upon their implementation of competitive business operating practices and business strategies. However, the options available to these enterprises are also closely related with the institutions, markets and organizations that constitute the business environment they operate in (OECD, 2004: 16). One of the ways to enhance their positions for the SMEs operating in a favourable business environment was reaching to new information and communication technologies, innovation in a broader sense that facilitates global reach and helps reduce the disadvantage of scale economies.

By a widely shared definition, innovation is the commercialization of invention (Schumpeter, 1942). One of the most common prejudices about innovation is that is considered to be able to develop a new brand or to produce solutions to customers with sophisticated demands via reaching to the latest information sources and working with highly trained R \& D staff development activities. However, today innovation is a very different phenomenon than its high-tech outlook (Savrul and Incekara, 2014: 2). The Oslo Manual on the other hand defines innovation as implementation of new or significantly modified goods or services or process, a new marketing method or a new organizational management in business practices, workplace organization or external relations (Savrul and Incekara, 2014: 2). That is to say it is a much more comprehensive phenomenon which affect administrative and technical, product and process, technological and architectural dimensions of an enterprise (Massa and Testa, 2008: 394).

SMEs generally don't have enough performance innovation to create radical changes in their industry or to offer something new to the world. As a result they lag behind its larger counterparts in terms production innovation however they have some advantages in utilizing it. They typically have direct contact to 
Journal of Global Strategic Management | V. 9 | N. 1 | 2015-June | isma.info | 125-133 | DOI:10.20460/JGSM.2015915634

customers and they have the potential of gaining valuable impulses in the form of customer feedback. They usually operate in a more casual way and have less levels of hierarchy which enable them to implement innovation easily. They are usually more flexible and fast decision makers nevertheless their being small limit their financial resources for internal innovation and they are confronted with the boundaries of their organizations In addition, they cannot cover all innovation activities required to successfully realize an innovation. Thus, open innovation is an important innovation strategy for SMEs (Tiwari and Buse, 2007: 7-8; (Vrande, 2009: 426; Brunswicker and Ehrenmann, 2013: 34).

\section{SMEs And Sources Of Innovation}

Because the role SMEs play in economic and technological development, their effort in innovation is exceptionally important. Although these small firms often have shortage of resources, they are successful innovators (Rosenbuscha et.al., 2011, 444). Even in the developed countries, SMEs are experiencing difficulties in gain ing access to innovation due to lack of financial resources and qualified staff. That is why a particular importance is given to SMEs innovation. As a result, obtaining technology and resources from external sources through strategic networks is much more intense in SMEs than the large firms. Together with those mentioned problems technological and political infrastructure deficiencies stands out of SMEs as a separate obstacle in developing countries (Hadjimanolis, 1999: 562).

Innovation is traditionally regarded as an activity performed by a single company. From a broader perspective, environmental factors shaped by innovation, expand the existing innovation possibilities and completely change the perspective of the traditional innovation systems. In this new business environment influenced by innovation either small or a large one, goal of the companies is not only to monetize their own business ideas but also to benefit from the external factors in the best way.

\section{Closed innovation}

Closed innovation model counsels firms to be strongly self-reliant and essentially offer them organizing innovation in their internal R\&D departments (Chesbrough, 2003). As a result in th is innovation model firms produce their own business ideas then develop, build, market, distribute, and support them on their own. Before the beginning of 2000s most of the innovation activities were closed and the existing efforts took place with in organization's boundaries and was performed by the own employees of the enterprise within its internal $R \& D$ function because general opinion was that internal resources are most reliable and trustworthy and always superior (PWC, 2015).

Many assumptions were offered for the implementation this approach some of which are still in use in some industries such as military and medicine in which the inventor should control the creation and management of invention at least for a while. However by the 20th century when universities and governments were involved in the commercial application of science general approach on the subject started to move away from closed innovation. Especially SMEs which don't have as much investment facility as the large firms started to enter into formal and informal partnerships to increase the collective innovative capability of both collaborators As a result the open model substituted the closed one for SMEs which prescribes enterprises to draw on both external and internal ideas and paths to the market, when enterprises look to discover and develop innovative opportunities (Asheim et.al., 2003: 24).

\section{Open innovation}

Organisations try for to obtain, maintain or increase their competitive advantage over their competitors. This is the primary reason for the existence of innovation, or the management of the innovation process. In line with other investigations of collaborative efforts, specific attention will be paid to the perspectives of transaction cost economics and the resource-based view of the firm arguably largely representing the economic organization and strategic management theories. Likewise the dynamic capabilities approach, knowledge-based view and technology-based view are also presented as viable perspectives to explain open collaborative innovation. Collectively, these theoretical perspectives provide an overview of the constructs and relationships that are relevant for studying and implementing collaborative knowledge sharing (Heredero and López, 2012: 2). 
Journal of Global Strategic Management | V. 9 | N. 1 | 2015-June | isma.info | 125-133 | DOI:10.20460/JGSM.2015915634

In this context, open innovation is a new paradig $m$ of innovation management and processes, popularity of which is rising recently. The purposive use of inflows and outflows of knowledge to accelerate internal innovation and expand the markets for external use of innovation is the scope of open innovation (Lichtenthaler, 2008, Marais and Schutte, 2009: 103-104). As a result comprises it makes up outside-in and inside-out movements of technologies and ideas at the same time which is associated with the terms technology acquisition and technology exploitation (West and Gallagher, 2006).

Knowledge flows across actors and space as embodied in machinery or components; and between industries or firms with very different degrees of R\&D-intensity and knowledge base characteristics. Low-tech firm users are linked to high-tech knowledge providers, and vice versa and to interfacing with leading suppliers, research institutes or universities that are more and more likely to be located outside of the immediate surrounding environment (Herstad et.al., 2008: 10). In such an environment open innovation provides business with flexible solutions and faster and richer innovation cycles; customers are provided with personalized, better optimized and affordable solutions and the services providers are supplied new ways in their service provisions, making the service creation and personalization more affordable for them (European Comission, 2015) which is of great importance for SMEs which are lack of resources to allocate for innovation however have to innovate in order to survive in the globalizing business environment. Consequently SMEs are getting into collaborative innovation processes day by day and new aspects and models of open innovation emerge. One of the ways SMEs get into collaborations with various actors in current business environment is modelled by Lee et.al. (2010) as in Figure 1.

\section{Figure 1. Open Innovation Models for SMEs}

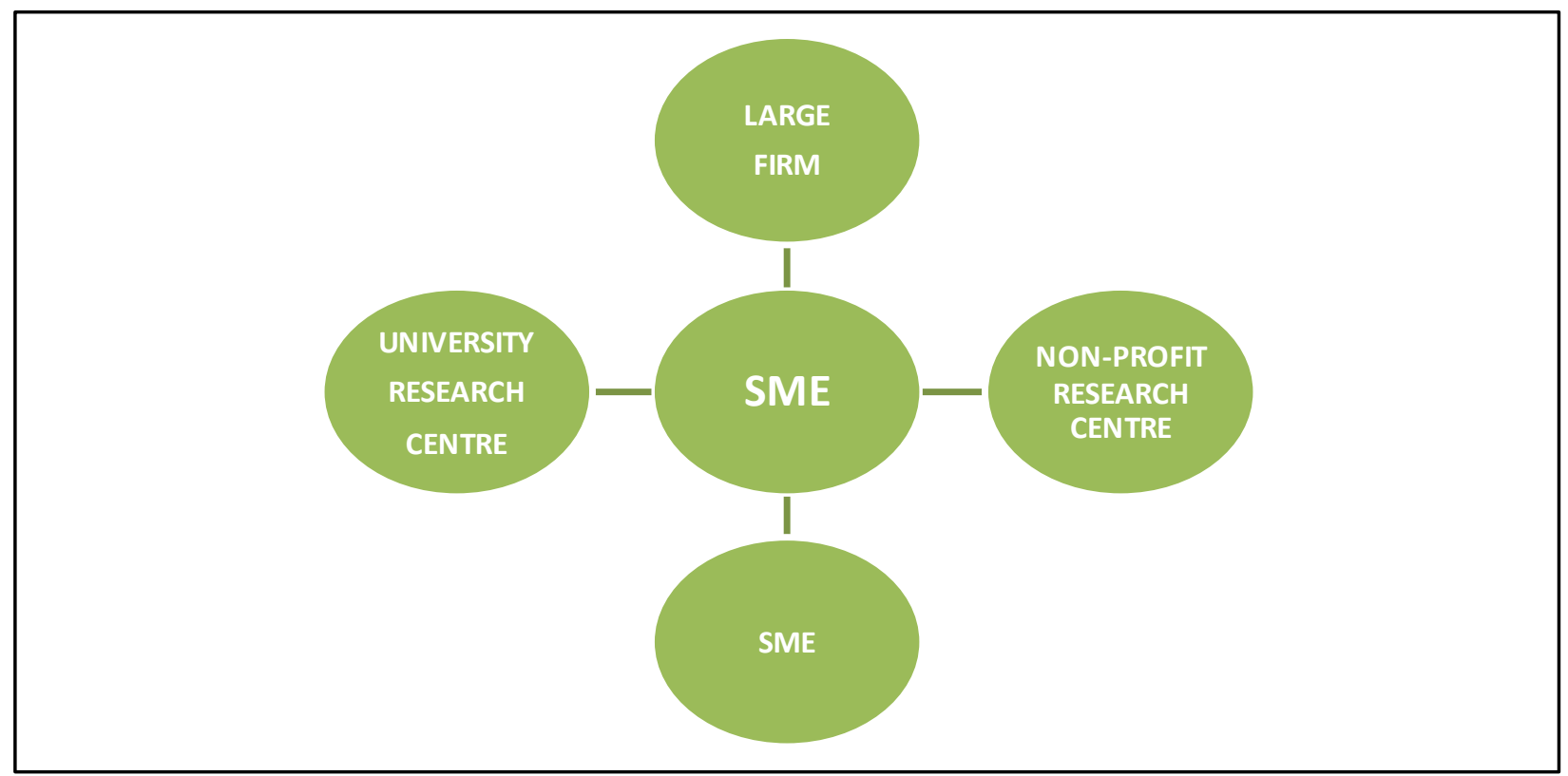

Figure 1 introducing a possible model of open innovation assert that while preserving their internal proficiency levels SMEs want to establish external partnerships to concentrate on various technologies. These partners may be the SMEs just like themselves or the larger firms, university research centres or even nonprofit organizations. However, with the fear of giving a way their technology to competitors, if all of these options are available the choice of the SMEs will generally be university research centres or non-profit organizations.

Open innovation has received increasingly attention in scientific research. Despite the huge interest the concept has raised among scholars and practitioners, there are still many unanswered questions in Open Innovation research and many areas where further investigation is needed. In particular, acknowledged as being open challenges for researchers in Open Innovation to investigate the relevance of Open Innovation as a new paradig $\mathrm{m}$ for industrial innovation management beyond high-tech industries to investigate how firms 
Journal of Global Strategic Management | V. 9 | N. 1 | 2015-June | isma.info | 125-133 | DOI:10.20460/JGSM.2015915634

can implement Open Innovation in practice (Vrande et.al. 2009: 423; Chiaroni, et.al, 2011: 34). In this respect the next section focuses the connection between the SMEs and the open innovation.

\section{THE RELATION BETWEEN OPEN INNOVATION AND ECONOMIC PERFORMANCE OF SMES}

The studies concerning the relation between firm size and innovation go back to a Schumpeter who had diverse opinions about the subjects. Schumpeter (1934) first argued that an industry with lots of s mall firms will encounter more innovation but his ideas in his Capitalis m, Socialis m, and Democracy (1943) was that large firms and the industries dominated by them contribute most to innovation. The later works summarizes his hypotheses as the success of innovative activities depends on market power, firm size and market structure.

A more up-to-date study is carried out by Cohen et.al. (1987) using data from the Federal Trade Commission's Line of Business Program. The results of their study present that the effect of overall firm size and business unit size on R\&D intensity is insignificant and they explain $1 \%$ of the variance in $R \& D$ intensity however almost $50 \%$ of the variance is explained by the impact of industry. As one of the exceptional studies on the topic Acs and Audretsch (1988) also studied on the relationship between firm size and innovation. The study shows that the relation between R\&D expenditures and innovative output is positive, firm size is related with the reaction given to market structures and the technologies to be invented is shaped by market structures.

As it is evident from the literature the effect of firm size on innovation performance is controversial however studies on the subject agree that either small or large R\&D investment is effective on firm performance. Since our focus is on SMEs and open innovation internal R\&D investments of the firms aren't taken into account and the external sources of R\&D such as higher education, government and non-profit research centres is dealt within the scope of the study.

\section{Data set}

The study covers turnover and GERD (Gross domestic expenditure on R\&D) data from 21 EU Countries covering 2007-2014 period. The data is collected from OECD and Eurostat databases and data 7 of the EU countries with missing values are excluded from the analysis. The analysis is formed of 4 variables; total turnover value of SMEs is indicated by TOV, GERD by higher education by GEHI, GERD by government by GEGO and GERD by non-profit research centres by GENP.

\section{Method}

In order to avoid spurious relationships between the variables, the variables used in the study should be stationary. Stationary of the variables has been tested with common unit root process developed by Levin, Lin and Chu (LLC) (2002) and assume individual unit root process developed by Im, Pesaran and Sh in (IPS) (2003) are performed. The results are summarized in Table 1.

Table 1. Panel Unit Root Test

\begin{tabular}{llllll}
\hline \hline Method & Variable & TOV & GEHI & GEGO & GENP \\
\hline \hline Levin, Lin \& Chu & stat & -19.8341 & -9.1904 & -17.7507 & -11.8870 \\
\cline { 2 - 6 } & p-value & 0.0000 & 0.0000 & 0.0000 & 0.0000 \\
\hline \hline \multirow{2}{*}{ Im, Peseran \& Shin } & stat & -7.2405 & -3.3095 & -6.4180 & -3.9149 \\
& p-value & 0.0000 & 0.0005 & 0.0000 & 0.0000 \\
\hline \hline
\end{tabular}


Journal of Global Strategic Management | V. 9 | N. 1 | 2015-June | isma.info | 125-133 | DOI:10.20460/JGSM.2015915634

The results of LLC and IPS tests show that displayed that first difference of variables are stationary at $1 \%$ significance level and they can be used in panel data analysis. Panel data has both cross section and period dimensions and countries form the cross section dimension while years are the period dimension. Individual effects of both countries and the years should be estimated. These effects are summarized in equation below in which "i" units are individual and " $t$ "s are the periods.

$$
T O V_{i t}=\beta_{1} G E H I_{i t}+\beta_{2} G E G O_{i t}+\beta_{3} G E N P_{i t}
$$

Table 2. Estimation Tests

\begin{tabular}{lcc}
\hline \hline Test & Statistic & d.f. \\
\hline \hline Redundant Fixed Effects Test & 2.064664 & $(20,123)$ \\
\hline \hline Hausman Test & 20.4394 & 3 \\
\hline \hline
\end{tabular}

The equation is estimated using Redundant Fixed Effects and Hausman Tests respectively to determine the appropriate model. As seen in Table 2. Because of the prob. value in FE test is smaller than 0,5 and the opposite case in the Hausman Test fixed effects model is found to be appropriate for the data set and it is analysed with Panel EGLS Fixed Effects test.

Table3. Panel EGLS (Fixed Effects)

\begin{tabular}{|c|c|c|c|c|}
\hline Variable & Coefficient & Std. Error & t-Statistic & Prob. \\
\hline $\mathrm{C}$ & 8838.397 & 3692.933 & 2.393327 & 0.0181 \\
\hline GEHI? & 41.83131 & 15.06999 & 2.775801 & 0.0063 \\
\hline GEGO? & 56.30088 & 19.70295 & 2.857486 & 0.0049 \\
\hline GENP? & 126.7044 & 101.6186 & 1.246863 & 0.2146 \\
\hline \multicolumn{5}{|l|}{ Weighted Statistics } \\
\hline R-squared & 0.4490 & \multicolumn{2}{|c|}{ Mean dependent var } & 12334.98 \\
\hline Adjusted R-squared & 0.4128 & \multicolumn{2}{|c|}{ S.D. dependentvar } & 75927.32 \\
\hline S.E. of regression & 57933.39 & \multicolumn{2}{|c|}{ Sum squared resid } & $4.60 \mathrm{E}+11$ \\
\hline Prob(F-statistic) & 0.0000 & & & \\
\hline
\end{tabular}

The test results shown in Table 3 indicate that the overall results produced by the analysis are significant and the variables are explaining the relationship between the variables at about $45 \%$ level. The individual examination of the variables is mostly harmonious with the overall results except from the GENP. Both GEHI and the GEGO variables are pretty significant and have a positive relationship with the dependent variable TOV. GENP standing for the R\&D expenditures of non-profit research centres on the other hand has been found insignificant. The analysis goes on with the examination of the reliability of the results.

Table 4. Correlation and Heteroskedasticity Tests

\begin{tabular}{lll}
\hline \hline \multirow{2}{*}{ Wooldridge Test for Autocorrelation } & $\mathrm{F}(1,20)$ & 0.0014 \\
\cline { 2 - 3 } & Prob $>\mathrm{F}$ & 0.9066 \\
\hline \hline \multirow{2}{*}{ Modified Wald Test for Heteroskedasticity } & Wald chi2(3) & 6.26 \\
\cline { 2 - 3 } & Prob >chi2 & 0.0997 \\
\hline \hline
\end{tabular}

Wooldridge Test for Autocorrelation and Modified Wald Test for Heteroskedasticity are performed respectively to check variance and autocorrelation problems. The tests rejected both heteroskedasticity and autocorrelation problems and proved that the results produced by the study are reliable. 


\section{CONCLUSION}

Because they are effective sources of employment generation and economic development, SMEs play dominant roles in both developed and developing economies. Although SMEs contribute significantly to the country host them, the economy and business environment changing rapidly due to the globalization process. Globalization helped many of the firm to grow and increase prosperity of developing countries to a degree but many others, particularly the SMEs operating locally, got the greatest damage from this new business environment which opened local markets to world.

Globalization and the competition created by it are anticipated to continue and grow. In this course more SMEs will surrender to deterioration of competitiveness or they have to find ways to enhance their positions in global markets. Many firms are putting innovation in to action to achieve necessary organizational adaptation to changes in the environment. However, most enterprises can no longer afford to innovate on their own due to the changes in production and marketing environment. Because the funds they can allocate to R\&D investment is limited, SMEs adopt open innovation practices.

In open innovation firms can use external ideas as their own, gain new paths to market and advance their technology. Therefore they are looking for external partnerships which may help with technology. These partners may be the SMEs just like themselves or the larger firms, university research centres or even nonprofit organizations. However, with the fear of giving away their technology to competitors, if all of these options are available the choice of the SMEs will generally be university research centres or non-profit research centres. The efficiency of these partnerships and the extend they cash on SMEs are the iss ue of interest. The answer to this is sue can also be helpful to policy makers in their next investment decision.

In this framework this study investigates the effects of open innovation on economic performance of SMEs. Economic performance of firms is meas ured with total turnover value of SMEs and external R\&D variables are GERD by higher education, govern ment and non-profit research centres. The results of the study indicate that the mentioned $R \& D$ variables are responsible for $45 \%$ of the changes in turnover value of SMEs. Individual examination shows that The R\&D investments achieved by the higher education institutions directly affect the performance of SMEs. It can be read as the success of Collaboration between SMEs and Higher Education Institutions. As much as the higher education, government practices are also effective on SMEs. This outcome can be associated with the recent financial and consulting support of government along side with the long term investments such as education institutions. Finally the effect of GERD achieved by non-profit research centres on SMEs is found to be insignificant. Although it is an unfavourable situation, in scope of the study it is expected because their share in GERD is not more than $1 \%$ in many countries while the share of higher education can go up to $40 \%$. 


\section{REFERENCES}

Acs, Zoltan J. and Audretsch, David B. (1988). Innovation in Large and Small Firms: An Empirical Analysis (1988). American Economic Review, Vol. 78, Issue 4, p. 678-690.

Asheim, Bjorn.T., Isaksen, Arne, Nauwelaers, C. Todtling, Franz. (2003). Regional Innovation Policy for Small-Medium Enterprises, Edward Elgar Publishing, UK.

Brunswicker, Sabine and Ehrenmann, Frank. (2013). Managing Open Innovation in SMEs: A Good Practice Example of a German Software Firm, International Journal of Industrial Engineering and Management (IJIEM),Vol.4, No.1, pp. 33-41.

Chesbrough, Henry William. (2003). Open Innovation: The New Imperative for Creating and Profiting from Technology, Harvard Business Press, USA.

Chiaroni, Davide, Chiesa, Vittorio and Frattini, Federico. (2011). The Open Innovation Journey: How Firms Dynamically Implement The Emerging Innovation Management Paradigm, Technovation, Vol.31, Issue 1, pp $34-43$.

Cohen, W. M., R. C. Levin, and D. C. Mowery. (1987). Firm size and R\&D intensity: A re-examination. Journal of Industrial Economics 35(4), 543-65.

European Comission. (2014). Innovation and SMEs - Keys to Prosperity, <http://ec.europa.eu/research/sme/leaflets/en/intro02.html>, (24.03.2015).

European Comission. (2015). Open and Participative Innovation, $<$ http://ec.europa.eu/digitalagenda/en/open-and-participative-innovation>, (24.03.2015).

Eurostat. (2014). SME Performance Review 2013/2014, DIV Econ.

Hadjimanolis, Athanasios.(1999). Barriers to Innovation for Smes in A Small Less Developed Country (Cyprus), Technovation, Vol.19, Issue 9, pp.561-570.

Hall, Bronwyn H. and Rosenberg, Nathan. (2010). Handbook of the Economics of Innovation, Elsevier, London.

Heredero, Carmen de Pablos, López, David. (2012). Open Innovation in Firms and Public Administrations: Technologies for Value Creation: Technologies for Value Creation, IGI Global, USA, (21.03.2015).

Herstad, Sverre J., Bloch, Carter, Ebersberger, Bernd, Velde, Els van de. (2008). Open Innovation And Globalisation: Theory, Evidence And Implications, Vision Era Dot Net, $\langle$ http://www.aksjonsprogrammet.no/vedlegg/opening_report_final.pdf〉, (21.03.2015).

Lee, Sungjoo, Park, Gwangman, Yoon, Byungun, Park,Jinwoo. (2010). Open innovation in SMEs - An Intermediated Network Model, Research Policy, Vol.39, Issue 2, pp.290-300.

Marais, Stephan J. and Schutte, Corne S.L. (2009). The Development of Open Innovation Models To Assist The Innovation Process, in SAIIE, Roodevallei, Gauteng, pp. 96-116.

Massa, Silvia and Testa, Stefania. (2008). Innovation and SMEs: Misaligned Perspectives and Goals among Entrepreneurs, Academics, and Policy Makers, Technovation, Volume 28, Issue 7, July 2008, Pages 393-407.

OECD. (2000). Enhancing the Competitiveness of SMEs in the Global Economy: Strategies and Policies, Conference for Ministers responsible for SMEs and Industry Ministers, Bologna, Italy, 14-15 June 2000.

OECD. (2004). Promoting Entrepreneurship and Innovative SMEs in A Global Economy:Towards A More Responsible and Inclusive Globalisation, 2nd OECD Conference of Ministers Responsible for Small and Medium-Sized Enterprises, 3-5 June 2007, Istanbul, Turkey.

OECD. (2013). Open innovation, in OECD, OECD Science, Technology and Industry Scoreboard 2013: Innovation for Growth, OECD Publishing, Paris.

OECD. (2015). Main Science and Technology Indicators, Paris, France. 
Journal of Global Strategic Management | V. 9 | N. 1 | 2015-June | isma.info | 125-133 | DOI:10.20460/JGSM.2015915634

PricewaterhouseCoopers LLP (PWC). (2015). Two views: Beyond Open and Closed Innovation, $\langle$ http://www.pwc.com/us/en/view/issue-14/two-views.jhtml>, (11.04.2015).

Rosenbuscha, Nina, Brinckmannb, Jan, Bauscha, Andreas. (2011). Is innovation always beneficial? A metaanalysis of the relationship between innovation and performance in SMEs, Journal of Business Venturing, Vol.26, Issue 4, pp.441-457.

Savrul, Mesut and Incekara, Ahmet. (2014). The Effect of R\&D Intensity on Innovation Performance: A Country Level Evaluation, 4th International Conference on Leaders hip, Technology and Innovation Management, 20-22 November 2014, Istanbul.

Schumpeter, Joseph A. (1934). The Theory of Economic Development. Harvard UP.

Schumpeter, Joseph A. (1942). Capitalism, Socialism, and Democracy. Harper, New York.

Tiwari, Rajnish and Buse, Stephan. (2007). Barriers to Innovation in SMEs: Can the Internationalization of R\&D Mitigate Their Effects? Proceedings of the First European Conference on Knowledge for Growth: Role and Dynamics of Corporate R\&D - Concord 2007, October 8-9, 2007, Seville, Spain.

Vrande, Vareska van de, Jong, Jeroen P.J. de, Vanhaverbeke, Wim, Rochemont, Maurice de. (2009). Open Innovation in SMEs: Trends, Motives and Management Challenges, Technovation, Vol.29, Issues 6-7, pp. 423-437.

West, Joel and Gallagher, Joel. (2006). Challenges of open innovation: The paradox of firm investment in open-source software. R\&D Management 36.3, pp.319-331.

World Trade Organization. (2013). E-Commerce In Developing Countries Opportunities and Challenges For Small And Medium-Sized Enterprises,

Zulkifli Mohd, Muhammad Abdul Kamal Char, Mohd Rushdan bin Yasoa, Zakiah Hassan (2010), Small and Medium Enterprises (SMEs) Competing in the Global Business Environment: A Case of Malaysia, International Business Research, Vol.3 No.1. 